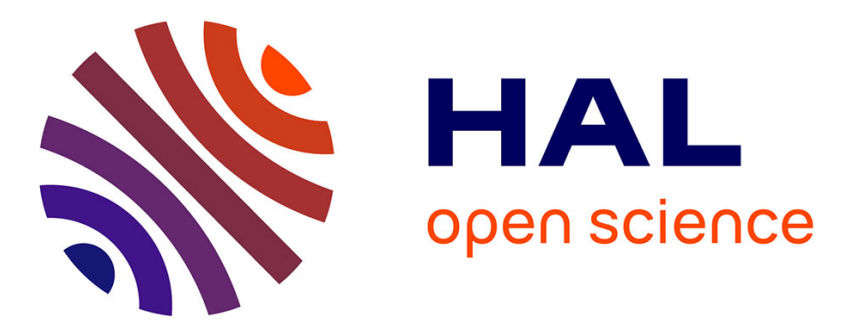

\title{
Peak Observer Based Self-tuning of Type-2 Fuzzy PID Controllers
}

\author{
Engin Yesil, Tufan Kumbasar, M. Furkan Dodurka, Ahmet Sakalli
}

\section{To cite this version:}

Engin Yesil, Tufan Kumbasar, M. Furkan Dodurka, Ahmet Sakalli. Peak Observer Based Self-tuning of Type-2 Fuzzy PID Controllers. 10th IFIP International Conference on Artificial Intelligence Applications and Innovations (AIAI), Sep 2014, Rhodes, Greece. pp.487-497, 10.1007/978-3-662-44654-6_48 . hal-01391350

\section{HAL Id: hal-01391350 \\ https://hal.inria.fr/hal-01391350}

Submitted on 3 Nov 2016

HAL is a multi-disciplinary open access archive for the deposit and dissemination of scientific research documents, whether they are published or not. The documents may come from teaching and research institutions in France or abroad, or from public or private research centers.
L'archive ouverte pluridisciplinaire HAL, est destinée au dépôt et à la diffusion de documents scientifiques de niveau recherche, publiés ou non, émanant des établissements d'enseignement et de recherche français ou étrangers, des laboratoires publics ou privés. 


\title{
Peak Observer based Self-tuning of Type-2 Fuzzy PID Controllers
}

\author{
Engin Yesil, Tufan Kumbasar, M. Furkan Dodurka, Ahmet Sakalli \\ Istanbul Technical University, Faculty of Electrical and Electronics Engineering, \\ Control and Automation Engineering Department, Maslak, TR-34469, Istanbul, Turkey \\ \{yesileng, kumbasart, dodurkam, sakallia\}@itu.edu.tr
}

\begin{abstract}
Fuzzy PID (proportional-integral-derivative) controllers are commonly used as an alternative to the conventional PID controllers. In order to improve the control system performance of these controllers many self-tuning methods are already studied. It is mostly observed that the self-tuning mechanism should tune the scaling factors of the fuzzy controller to enhance the transient system performance. On the other hand, these studies only focus on the ordinary (Type-1) Fuzzy PID controllers. In this study, Type-2 Fuzzy PID controllers are studied and a peak observer based self-tuning method is proposed for these controllers. In order to show the benefit of the proposed approach, several Matlab simulations are performed where different type of fuzzy control structures are compared. The results obtained from the simulation studies clearly show the advantage of the proposed approach.
\end{abstract}

Keywords: Type-2 Fuzzy PID controllers, self-tuning, peak observer.

\section{Introduction}

Ordinary (type-1) Fuzzy PID (proportional-integral-derivative) controllers (FPID) are accepted as an alternative to conventional PID controllers since they are analogous to the PID controllers from the input-output relationship point of view [1-3]. Numerous techniques have been developed in the literature for analyzing and designing a wide variety of Type-1 Fuzzy PID (T1-FPID) control systems [3-6]. The design parameters of the T1-FPID controllers can be summarized within two groups, structural parameters and tuning parameters [6]. The structural parameters include input/output variables to fuzzy inference such as fuzzy sets, Membership Functions (MFs) shapes, rules and inference mechanism. Tuning parameters include input/output Scaling Factors (SFs) and the parameters of the MFs. Starting with the pioneering study by Qiao and Mizumoto [3], various online tuning mechanisms have been presented to improve the control performance of the fuzzy control system in presence of parameter variations and nonlinearities [7-10]. Thus, Self-Tuning Type-1 Fuzzy PID (STT1-FPID) controllers have been proposed where the SFs or the parameters of MFs have been adjusted in an online manner [7-12]. However, the main research focus was on the tuning of the SFs since their effect on the system's response can easily be observed [8-9]. The presented self-tuning

adfa, p. 1, 2011.

(C) Springer-Verlag Berlin Heidelberg 2011 
mechanisms for the SFs provide extra degrees of freedom to the fuzzy control structure, and also enhance new tuning structures which have to be determined as updating functions or extra fuzzy inference mechanisms.

Recently, researchers began investigating Interval Type-2 Fuzzy Logic Controllers (IT2-FLCs) which have demonstrated significant control performance improvements in comparison to its type-1 counterpart [13-15]. It has been shown in various works that the T1-FPID controllers using Type-1 Fuzzy Sets (T1-FSs) might not be able to fully handle the high levels of uncertainties associated with control applications while the Interval Type-2 Fuzzy PID (IT2-FPID) controller using Interval Type-2 Fuzzy Sets (IT2-FSs) might be able to handle such uncertainties to produce a better control performance [15-17]. It has been shown that IT2-FPIDs achieve better control performances because of the additional degree of freedom provided by the Footprint of Uncertainty (FOU) in their antecedent MFs [14-15, 18]. In literature, the design of the IT2-FPID controllers is usually solved by extending MFs of an existing T1-FPID controller or by employing optimization algorithms [19-21].

In this study, the peak observer (PO) based self-tuning method, which was first proposed for T1-FPID controllers, is extended for IT2-FPID controllers. Till now, there is a very limited research on the self-tuning methods for the Type-2 Fuzzy Logic Controllers. The benefit of this approach is examined via various simulation studies performed on First Order plus Dead Time (FOPDT) systems. The simulation results clearly show that IT2-FPID controller achieve a better performance than T1-FPID and PO based T1FPID controllers. When the proposed self-tuning approach is employed to the IT2-FPID controller the control system performance increases significantly.

\section{The Design of Fuzzy PID Controllers}

Interval Type-2 Fuzzy PID controllers are generalized forms of Type-1 Fuzzy PID controllers, which are mostly mentioned as an alternative to conventional PID controllers since they are analogous to the PID controllers from the input-output relationship point of view [1-3]. PID controllers are widely used in many control areas such as process control, adaptive control, robust control, nonlinear control, automation and robotics and they are still the most used controller type in the industry [22]. The design strategies of conventional PID controllers depends on the mathematical model of the system, however conventional PID controllers may not provide satisfactory results in case of imperfect model. Conventional PID controllers provide a linear transformation or mapping between their inputs and outputs while Fuzzy PID controllers provide a nonlinear transformation or mapping between their inputs and outputs.

In literature, various fuzzy controller structures are proposed including PD-type (Proportional-Derivative), PI-type (Proportional-Integral) and PID-type [4, 9]. In this context, fuzzy controllers are constructed by choosing the inputs to the error (e) and derivative of the error $(\dot{e})$ and the output as the control signal (u). The inputs of Fuzzy Logic Controllers (FLCs) (regardless to the type of the controller) is as follow

$$
e=r-y
$$




$$
\dot{e}=\frac{d e}{d t}=\frac{d(r-y)}{d t}
$$

where $r$ is the reference signal or setpoint and $y$ is the system output. In fuzzy controller structures (regardless to the type of the controller), input SFs normalize the inputs to the universe of discourse, particularly, $K_{e}$ normalizes the error signal and $K_{d}$ normalize the derivative of error signal as follow

$$
\begin{aligned}
& E=K_{e} e, E \in[-1,1] \\
& \dot{E}=K_{d} \dot{e}, \dot{E} \in[-1,1]
\end{aligned}
$$

where $E$ is the normalized error signal of the FLC and $\dot{E}$ is the normalized derivative of error signal of the FLC. Here, the universe of discourses of the inputs $(E$ and $\dot{E})$ is defined in the interval $[-1,1]$. The FPID controller structure including inputs, SFs and the FLC (T1-FLC or IT2-FLC) is illustrated as in Fig. $1 . K_{a}$ is a constant gain, and $K_{b}$ is the integral gain of the output of the FLC. Here also notice that, output SFs make the control signal applicable for a particular problem or a real life problem because the output of the FLC could only take values in the interval $[-1,1]$ due to its universe of discourse of the output MFs. Then the generalized formulation of the output of a FLC that used in this study is as follows:

$$
u=K_{a} U+K_{b} \int U d t, U \in[-1,1]
$$

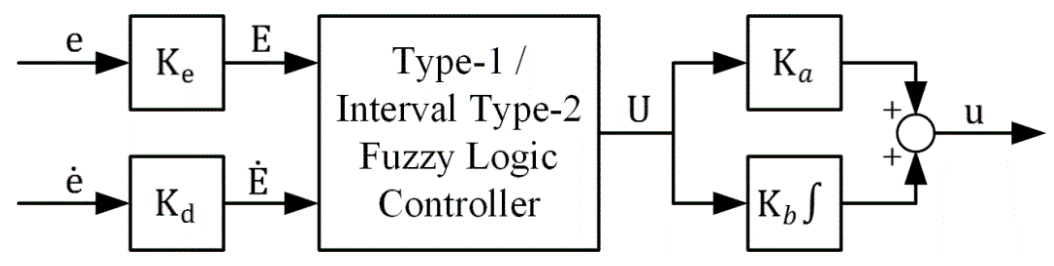

Fig. 1. Fuzzy PID Controller

\subsection{The Type-1 Fuzzy PID Controller Structure}

In this subsection, the internal structure and the design strategies of the employed T1FPID controllers are presented. The rule structure is as follows:

$$
\begin{gathered}
R_{q}: \text { If } E \text { is } A_{1 j} \text { and } \dot{E} \text { is } A_{2 j} \text { THEN } U \text { is } C_{q}, \\
\quad i, j=1,2,3 ; q=1, \ldots, Q=9
\end{gathered}
$$

where $A_{1 j}$ is and $A_{2 j}$ are the antecedent MFs for the inputs $E$ and $\dot{E}$, respectively, $C_{q}$ is the consequent crisp set and $Q$ is the number of rules. In the handled T1-FPID structure, a symmetrical $3 \times 3$ rule base is used as shown in Fig. 2a. Here, three Type-1 Fuzzy Sets (T1-FSs) for each input domain $(E$ and $E)$ are used and they are denoted as $N$ (Negative), $Z$ (Zero) and $P$ (Positive). The T1-FSs of the T1-FLC are defined in [-1 1] interval as shown in Fig. 2b. The consequent part is defined with five singleton consequents, as shown in Fig. 2c. The implemented T1-FLCs use the product implication and the weighted average defuzzification method. 


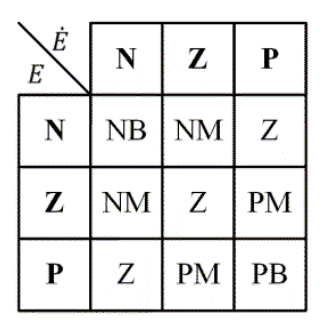

(a)

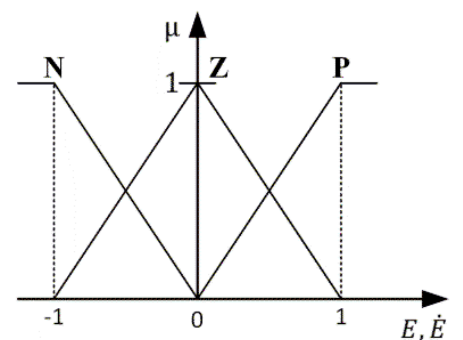

(b)

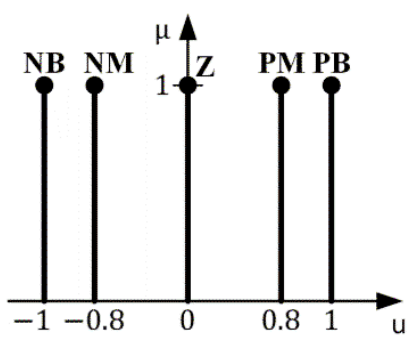

(c)

Fig. 2. (a) The fuzzy rule base, (b) the antecedent MFs, (c) the consequent MFs used for the FPID controllers.

\subsection{The Interval Type-2 Fuzzy PID Controller Structure}

In this subsection, the general structure of the employed IT2-FPID controller is presented. In the design of the IT2-FPID, the same symmetrical $3 \times 3$ rule base given in Fig. $2 \mathrm{a}$ and consequent MFs of T1-FPID illustrated in Fig. $2 \mathrm{c}$ are used. Thus, the rule structure of the IT2-FLC is as follows:

$$
\begin{gathered}
R_{q}: \text { IF } E \text { is } \tilde{A}_{1 i} \text { and } \dot{E} \text { is } \tilde{A}_{2 j} \text { THEN } U \text { is } C_{q}, \\
\quad i, j=1,2,3 ; \quad q=1, \ldots, Q=9
\end{gathered}
$$

where $C_{q}$ is the consequent crisp set, $Q$ is the number of rules and $\tilde{A}_{1 i}$ and $\tilde{A}_{2 j}$ are the antecedent Interval Type-2 Fuzzy Sets (IT2-FSs). We will denote the IT2-FSs as $N$ (Negative), $Z$ (Zero) and $P$ (Positive). The antecedent IT2-FSs can be described in terms of upper MFs $\left(\bar{\mu}_{\tilde{A}_{1 i}}\right.$ and $\left.\bar{\mu}_{\tilde{A}_{2 i}}\right)$ and lower MFs $\left(\underline{\mu}_{\tilde{A}_{1 i}}\right.$ and $\left.\underline{\mu}_{\tilde{A}_{2 i}}\right)$ to form the Foot of Uncertainty (FOU), which provides extra degree of freedom in IT2-FSs. The antecedent IT2-FSs are defined again in $\left[\begin{array}{ll}-1 & 1\end{array}\right]$ interval. Thus, the FOU will be created by the heights of the lower MFs $\left(\mathrm{m}_{1}\right.$ and $\left.\mathrm{m}_{2}\right)$ of the IT2-FLC. The implemented IT2-FLC uses the center of sets type reduction/ defuzzification method [23].

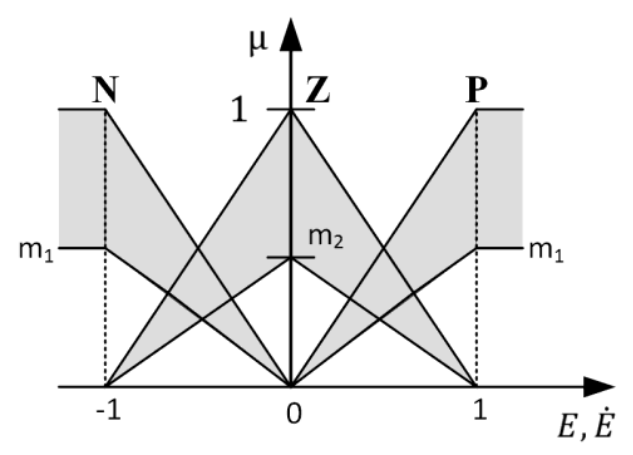

Fig. 3. Interval Type-2 Fuzzy Sets used for IT2-PID controller 


\section{The Peak Observer based Self-tuning Method}

As shown in Fig. 1, the actual control signal of the closed loop system is a function of scaling factors and the output of the FLC as $u=f\left(U, K_{a}, K_{b}\right)$ or $u=$ $f\left(U, \int U, K_{a}, K_{b}\right)$. The FLC performs a nonlinear mapping between its inputs and output, so the output of the FLC can also be expressed as a function of its inputs namely, error and derivative of the error as $U=f(E, \dot{E})$ or $U=f\left(e, \dot{e}, K_{e}, K_{d}\right)$. Note that $f($. represents a functional mapping. Consequently, the FPID controller structure becomes analogous to conventional PID structure. This analysis was examined in detail by considering the input space into several subspaces and mathematical expression of MFs [3] and the control signal can be written as

$$
u=K_{a} K_{0}+K_{b} K_{0} t+\left(K_{a} K_{e} K_{1}+K_{b} K_{d} K_{2}\right) e+\left(K_{b} K_{e} K_{1}\right) \int e d t+\left(K_{a} K_{d} K_{2}\right) \dot{e}
$$

where $K_{0}, K_{1}$ and $K_{2}$ are the constants which are calculated with respect to antecendent and consequent membership functions. They are calculated with respect to values of consequent sets and apexes of the antecedent membership functions for corresponding inputs and subspaces. Here, $K_{0}$ is a nonlinear term, which converges to zero by time. So one can say that a FPID controller is similar to a conventional PID controller with variable gains. Then after neglecting the nonlinear term for the steady state, the PID equivalent control components of FPID can be achieved as follows

$$
\begin{gathered}
K_{p}=K_{a} K_{e} K_{1}+K_{b} K_{d} K_{2} \\
K_{I}=K_{b} K_{e} K_{1} \\
K_{D}=K_{a} K_{d} K_{2}
\end{gathered}
$$

where $K_{p}$ is the proportional gain, $K_{I}$ is the integral gain and the $K_{D}$ is the derivative gain of the fuzzy controller.

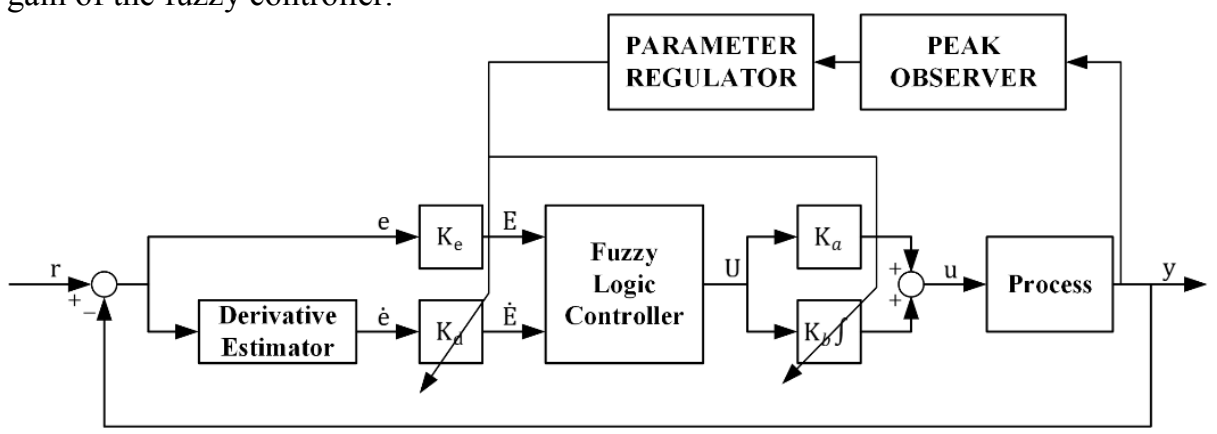

Fig. 4. Peak observer based self-tuning for Fuzzy PID controllers

The peak observer based self-tuning method for T1-FPID controllers has been proposed in [3]. The block diagram of the proposed method is shown in Fig. 4. The peak observer observes the output of the system and transmits a signal at each peak time and 
measures the absolute peak value. The parameter regulator tunes the controller parameters $\mathrm{K}_{\mathrm{d}}$ and $\mathrm{K}_{\mathrm{b}}$ simultaneously at each peak time according to the peak value. The algorithm for tuning these parameters is as follows:

$$
K_{d}=\frac{K_{d_{s}}}{\delta_{k}}, K_{b}=\delta_{k} K_{b_{S}}
$$

where $K_{d_{s}}$ and $K_{b_{s}}$ are the initial values of $K_{d}$ and $K_{b}, \delta_{k}$ are the peak values. It can easily be deduced from the relation given in (9) that if in the meanwhile of decreasing $K_{b}, K_{d}$ is increased in the same rate as $K_{b}$ is decreased, the equivalent proportional control strength will remain unchanged. Then, the system can always keep quick reaction against the error under this condition. This is achieved by updating the integral coefficient as the reciprocal of the derivative coefficient. As it is seen from (12), the integral factor is decreased in a direct proportion to the peak error value.

\section{$4 \quad$ Simulation Studies}

In this section, the performance of the proposed self-tuning method for IT2-FPID controllers is examined via various cooperative simulations. For this purpose, different processes are used for simulations but as it is well-known a large number of industrial plants can be modeled by a first-order plus dead time (FOPDT) transfer function. The wide use of FOPDT is due both to its simplicity as well as its ability to capture the essential dynamics of several industrial processes. Therefore, the results obtained only for FOPDT process are presented here. The transfer function of FOPDT is as follows:

$$
G(s)=\frac{K}{T s+1} e^{-L s}
$$

where $\mathrm{K}$ is the process gain, $\mathrm{T}$ is the time constant and finally $\mathrm{L}$ is the time delay.

In the simulations, four different control schemes, namely Type-1 Fuzzy PID Controller (T1-FPID), Peak Observer based Type-1 Fuzzy PID Controller (POT1-FPID), Interval Type-2 Fuzzy PID Controller (IT2-FPID), and the proposed Peak Observer based Interval Type-2 Fuzzy PID Controller (POIT2-FPID), are used. In order to compare the performance of transient responses of the proposed POIT2-FPID controller with other fuzzy controllers, the following four performance measures are considered: i) Integral Square Error (ISE) which is defined as

$$
\text { ISE }=\int_{0}^{\infty}(r(t)-y(t))^{2} d t
$$

ii) Integral Absolute Error (IAE) which is defined as

$$
\text { IAE }=\int_{0}^{\infty}|r(t)-y(t)| d t
$$

iii) Integral Time Absolute Error (ITAE) which is defined as

$$
\text { ITAE }=\int_{0}^{\infty} t|r(t)-y(t)| d t
$$

iv) Total Variation (TV) [11] of the control input $u(t)$, which is defined as 


$$
\mathrm{TV}=\sum_{\mathrm{i}=1}^{\infty}\left|\mathrm{u}_{\mathrm{i}+1}-\mathrm{u}_{\mathrm{i}}\right|
$$

As the first step, the nominal process parameters are set to $\mathrm{K}=1, \mathrm{~T}=1$ and $\mathrm{L}=0.2$. The sampling time of the simulation is set to $0.05 \mathrm{~s}$ and noise is added to the process output to make the simulations more realistic. Then the input SFs of the T1-FPID controller are designed in order to have a response without an overshoot but small rise time and settling time. For this purpose, first the input scaling factor of the error $\left(\mathrm{K}_{\mathrm{e}}\right)$ is calculated as

$$
K_{e}=\frac{1}{r\left(t_{f}\right)-y\left(t_{f}\right)}
$$

where $r\left(t_{f}\right)$ and $y\left(t_{f}\right)$ are the values of the reference and system output at the time of the reference variation. Since the unit step changes are studied for the simulations $\mathrm{K}_{\mathrm{e}}$ is set to 1 , then the other scaling factors are determined as $\mathrm{K}_{\mathrm{d}}=0.5141, \mathrm{~K}_{\mathrm{a}}=0.077, \mathrm{~K}_{\mathrm{b}}=$ 7.336 after optimization. As the second step, the IT2-FPID controller is design using the same scaling factors obtained for T1-FPID controller. For the design procedure only the height of the lower membership functions $\left(\mathrm{m}_{1}\right.$ and $\left.\mathrm{m}_{2}\right)$ are designed. After the optimization procedure, $\mathrm{m}_{1}$ and $\mathrm{m}_{2}$ are set to 0.3 and 0.9 , respectively. The step responses of the process for four different control schemes are illustrated in Fig. 5. As clearly seen from Fig. 5, the set-point following performance of all fuzzy controllers are very close to each other for the nominal process. Since there is no overshoot, the self-tuning mechanism did not tune the SFs.

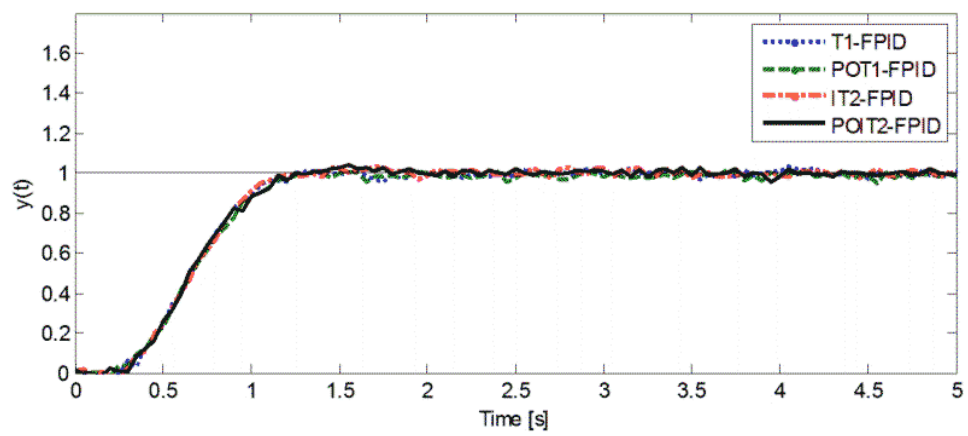

Fig. 5. The set-point following performance of the fuzzy controllers for the nominal process.

In order to show the benefit of using IT2-PID controllers, and the proposed PO based Type-2 Fuzzy PID controller the system parameters of the process are perturbed. The step responses of four controller for the first perturbed process, which has the parameters as $\mathrm{K}=1.3, \mathrm{~T}=1.9, \mathrm{~L}=0.4$, is given in Fig. 6a. For this case, IT2-FPID controller gives a better set-point following performance than the T1-FPID controller because of its extra degree of freedom. As it is seen in Fig. $6 \mathrm{~b}$ and Fig. $6 \mathrm{c}$, the two scaling factors $\left(\mathrm{K}_{\mathrm{d}}\right.$ and $\mathrm{K}_{\mathrm{b}}$ ) of the fuzzy controllers are tuned as the overshoots occurs, therefore the performance of the fuzzy controllers is improved drastically. The control signals illustrated in Fig. 6d, shows that IT2-FPID controller with peak-observer based self-tuning mechanism has a smoother control action in comparison to the other fuzzy controllers. 


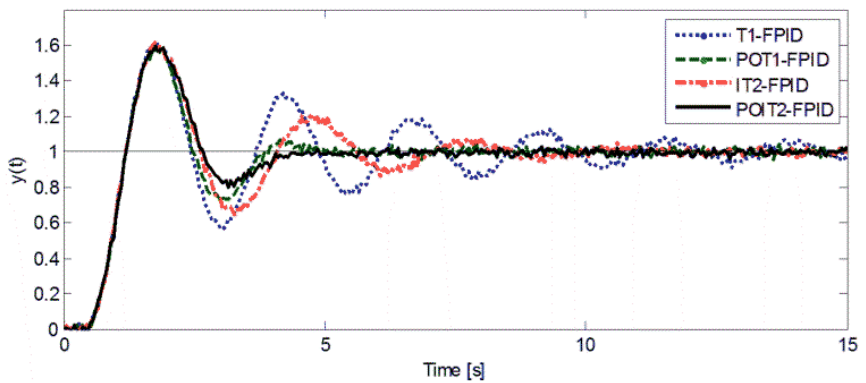

(a)

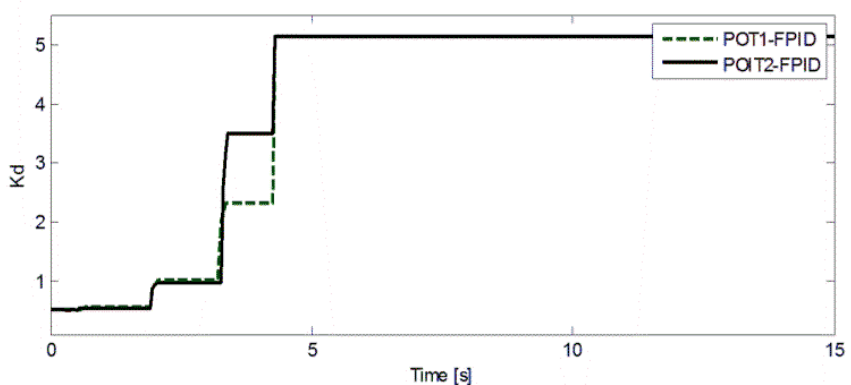

(b)

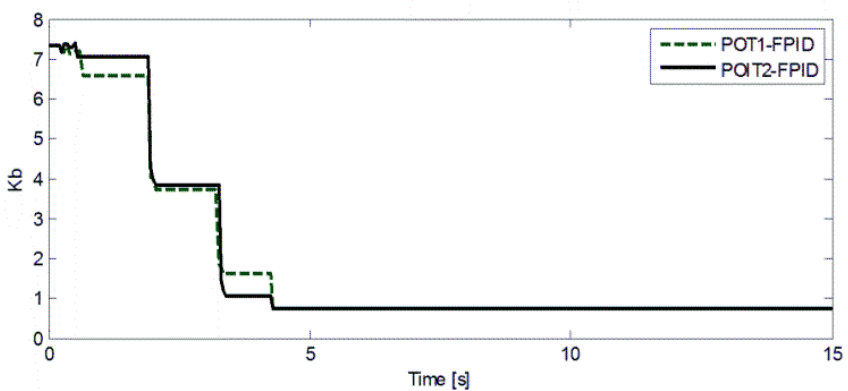

(c)

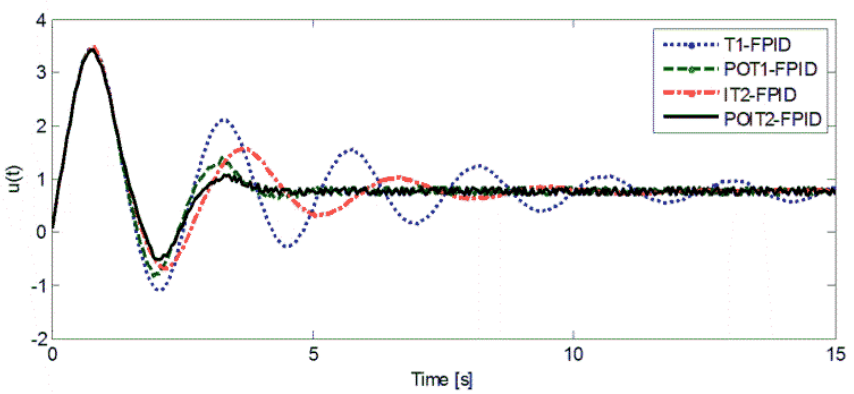

(d)

Fig. 6. The first the perturbed process $(K=1.3, T=1.9, \mathrm{~L}=0.4)$ : (a) The process output; (b) The change of $\mathrm{Kb}$; (c) The change of $\mathrm{Kd}$; (d) The control signals. 


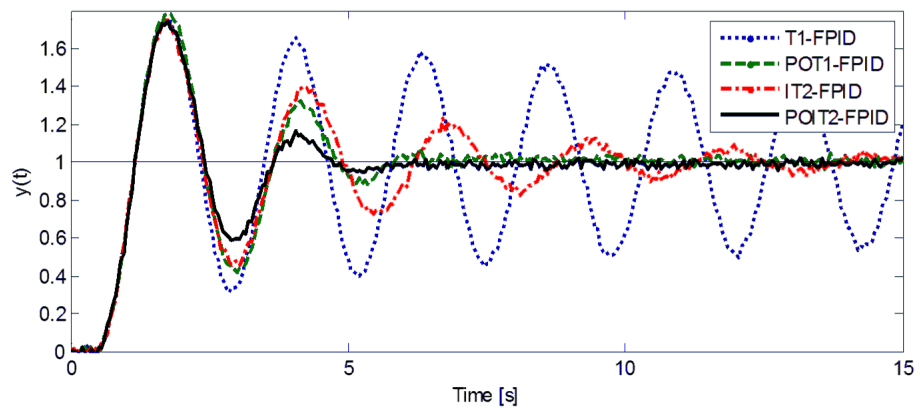

(a)

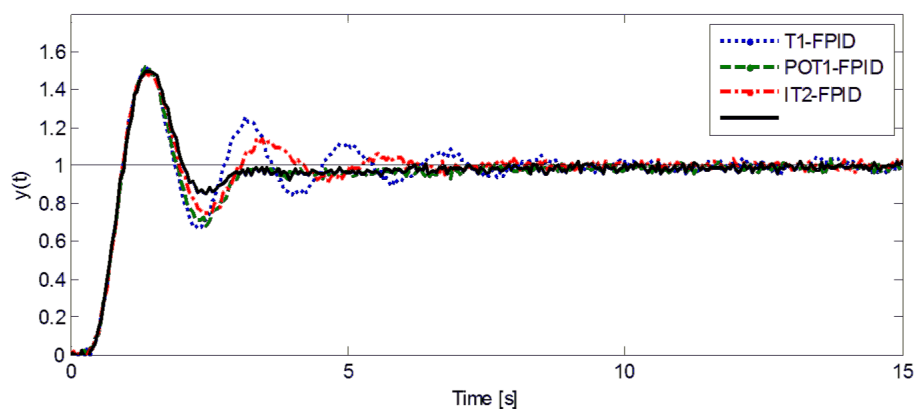

(b)

Fig. 7. The set-point following performance of the fuzzy controllers for the perturbed processes: (a) $\mathrm{K}=1.1, \mathrm{~T}=1.3, \mathrm{~L}=0.45$; (b) $\mathrm{K}=3, \mathrm{~T}=3, \mathrm{~L}=0.3$.

The simulation results obtained for the first perturbed process show that IT2-FPID controller has a better set-point following performance than the T1-FPID controller because of FOU. Moreover, the peak observer based self-tuning mechanism improves the performance of the fuzzy controllers. The best performance from the point of transient response is obtained by the proposed IT2-FPID controller with the peak observer mechanism. Moreover, two more simulations are performed for two other perturbed processes and the control performances are given in Fig. 7. Parallel to the first simulation results, IT2-FPID controller always outperforms the T1-FPID controller. The Peak Observer based T1-FPID is more robust against parametric uncertainties; consequently the process output inherits smaller oscillations. When the proposed Peak Observer selftuning method is employed to IT2-FPID controller, its performance again increases drastically.

The performance results of the fuzzy controllers are tabulated in Table 1. As it is seen from Table 1, the IT2-FPID controller is always better than the T1-FPID controller because of the additional degree of freedom provided by the FOU in their antecedent MFs. Also, the peak observer self-tuning methods improve the fuzzy control system performance. On the other hand, since the peak observer changes the scaling factors of the fuzzy controller, the control signal varies and thus results with higher TV values compared to the counterparts without a self-tuning mechanism. 
Table 1. Simulation comparison using different performance measures.

\begin{tabular}{|c|c|c|c|c|c|}
\hline Process & Controller & ISE & IAE & ITAE & TV \\
\hline \multirow{4}{*}{$\begin{array}{l}\text { Nominal Process } \\
\mathrm{K}=1, \mathrm{~T}=1, \mathrm{~L}=0.2\end{array}$} & T1-FPID & 0.552 & 0.842 & 1.564 & 0.409 \\
\hline & POT1-FPID & 0.547 & 0.872 & 1.745 & 0.970 \\
\hline & IT2-FPID & 0.550 & 0.842 & 1.590 & 0.364 \\
\hline & POIT2-FPID & 0.550 & 0.838 & 1.508 & 0.926 \\
\hline \multirow{4}{*}{$\begin{array}{l}\text { Perturbed Process } \\
\qquad \begin{array}{c}\mathrm{K}=1.3, \mathrm{~T}=1.9 \\
\mathrm{~L}=0.4\end{array}\end{array}$} & T1-FPID & 1.272 & 2.677 & 9.430 & 1.589 \\
\hline & POT1-FPID & 1.050 & 1.755 & 3.357 & 1.401 \\
\hline & IT2-FPID & 1.160 & 2.181 & 5.497 & 1.000 \\
\hline & POIT2-FPID & 1.055 & 1.733 & 3.240 & 1.275 \\
\hline \multirow{4}{*}{$\begin{array}{l}\text { Perturbed Process } \\
\qquad \begin{array}{c}\mathrm{K}=1.1, \mathrm{~T}=1.3 \\
\mathrm{~L}=0.45\end{array}\end{array}$} & T1-FPID & 2.969 & 5.739 & 36.223 & 3.756 \\
\hline & POT1-FPID & 1.457 & 2.423 & 5.659 & 1.690 \\
\hline & IT2-FPID & 1.503 & 2.981 & 10.394 & 1.476 \\
\hline & POIT2-FPID & 1.252 & 2.062 & 4.310 & 1.461 \\
\hline \multirow{4}{*}{$\begin{array}{l}\text { Perturbed Process } \\
\mathrm{K}=3, \mathrm{~T}=3, \mathrm{~L}=0.3\end{array}$} & T1-FPID & 0.836 & 1.710 & 4.355 & 1.166 \\
\hline & POT1-FPID & 0.789 & 1.488 & 3.278 & 1.290 \\
\hline & IT2-FPID & 0.789 & 1.472 & 2.979 & 0.768 \\
\hline & POIT2-FPID & 0.763 & 1.382 & 2.940 & 1.173 \\
\hline
\end{tabular}

\section{Conclusion}

In this study, the peak observer based self-tuning method, which involves a peak observer and parameter regulator mechanisms, is extended to IT2-FPID Controllers. The advantage of the proposed approach is tested via Matlab simulations and the control system performance of the proposed method is compared with T1-PID controllers with and without a self-tuning mechanism, and also with an IT2-FPID controller without a self-tuning method. The obtained result clearly shows that peak-observer based selftuning approach improved the performance in comparison to the IT2-FPID controller. As a future work, this approach will be implemented in a PLC and real-time experiments will be performed.

Acknowledgments. This research is supported by the Scientific and Technological Research Council of Turkey (TUBITAK) under the project (113E206). All of these supports are appreciated.

\section{References}

1. Galichet, S., Foulloy, L.: Fuzzy controllers: synthesis and equivalences. IEEE Transactions on Fuzzy Systems, vol. 3, no. 2, pp. 140-148 (1995)

2. Huang, T. T., Chung, H. Y., Lin J. J.: A fuzzy PID controller being like parameter varying PID. IEEE International Fuzzy Systems Conference Proceeding, vol. 1, pp. 269-275 (1999) 
3. Qiao, W. Z., Mizumoto, M.: PID type fuzzy controller and parameters adaptive method. Fuzzy Sets and Systems, vol. 78, no. 1, pp. 23-35 (1996)

4. Li, H. X., Gatland, H. B.: Conventional fuzzy control and its enhancement. IEEE Transactions on Systems, Man and Cybernetics Part B, vol. 26, no. 5, pp. 791-797 (1996)

5. Duan, X. G., Li, H. X., Deng, H.: Effective tuning method for fuzzy PID with internal model control. Industrial \& Engineering Chemistry Research, vol. 47, pp. 8317-8323 (2008)

6. Hu, B., Mann, G. K. I., Gasine, R. G.: New methodology for analytical and optimal design of fuzzy PID controllers. IEEE Transactions on Fuzzy Systems, vol. 7, no. 5, pp. 521-539 (1999)

7. Mudi, R. K., Pal, N. R.: A robust self-tuning scheme for PI- and PD-type fuzzy controllers. IEEE Transactions on Fuzzy Systems, vol. 7, no. 1, pp. 2-16, (1999)

8. Woo, Z. W., Chung, H. Y., Lin, J. J.: A PID-type fuzzy controller with self-tuning scaling factors. Fuzzy Sets Systems, vol. 115, pp. 321-326 (2000)

9. Guzelkaya, M., Eksin, I., Yesil, E.: Self-tuning of PID-type fuzzy logic controller coefficients via relative rate observer. Engineering Applications of Artificial Intelligence, vol. 16, pp. 227-236 (2003)

10. Ahn, K. K., Truong, D. Q.: Online tuning fuzzy PID controller using robust extended Kalman filter. Journal of Process Control, vol. 19, pp. 1011-1023 (2009)

11. Karasakal, O., Guzelkaya, M., Eksin, I., Yesil, E.: An error-based on-line rule weight adjustment method for fuzzy PID controllers. Expert Systems and Applications, vol. 38, no. 8, pp. 10124-10132 (2011)

12. Karasakal, O., Guzelkaya, M., Eksin, I., Yesil, E., Kumbasar, T.: Online tuning of fuzzy PID controllers via rule weighting based on normalized acceleration. Engineering Applications of Artificial Intelligence, vol. 26, no. 1, pp. 184-197 (2013)

13. Wu, D., Tan, W. W.: Interval Type-2 Fuzzy PI Controllers: Why They Are More Robust. IEEE International Conference on Granular Computing, pp. 802-807 (2010)

14. Wu, D.: On the Fundamental Differences between Type-1 and Interval Type-2 Fuzzy Logic Controllers. Transactions on Fuzzy Systems, vol. 20, no. 5, pp. 832-848 (2012)

15. Hagras, H.: A Hierarchical Type-2 Fuzzy Logic Control Architecture for Autonomous Mobile Robots. IEEE Transactions on Fuzzy Systems, vol. 12, no. 4 pp. 524-539 (2004)

16. Castillo, O., Melin, P.: Type-2 Fuzzy Logic Theory and Applications. Springer-Verlag, Berlin (2008)

17. Wu, D., Tan, W. W.: A simplified type-2 fuzzy logic controller for real-time control. ISA Transactions, vol. 45 , no. 4, pp. 503-516 (2006)

18. Kumbasar, T., Eksin, I., Guzelkaya M., Yesil, E.: Type-2 fuzzy model based controller design for neutralization processes. ISA Transactions, vol. 51, no. 2, pp. 277-287 (2012)

19. Kumbasar, H. Hagras: Big Bang-Big Crunch optimization based interval type-2 fuzzy PID cascade controller design strategy, Inform. Sci., http://dx.doi.org/10.1016/j.ins.2014.06.005, (2014)

20. Kumbasar T.: A simple design method for interval type-2 fuzzy PID controllers. Soft Computing, pp. 1-12 (2013)

21. Yesil, E.: Interval type-2 fuzzy PID load frequency controller using Big Bang-Big Crunch optimization. Applied Soft Computing, vol. 15, pp. 100-112 (2014)

22. Astrom, K.J., Hagglund, T.: Advanced PID Control, ISA ,2005

23. Liang, Q., Mendel, J. M: Interval type-2 fuzzy logic systems: theory and design. IEEE Transactions on Fuzzy Systems, vol. 8, no. 5, pp. 535-550 (2000) 